\title{
Special Role of Credit Institutions in the Russian National AML/CFT System
}

\section{Lebedeva M.E.}

\author{
Doctor of economics, professor of banking department, Saint-Petersburg State University of Economics,
} Email: lemar3@yandex.ru

Molova L.A.

Graduate student of banking department, Saint-Petersburg State University of Economics Email: emeraldmay@rambler.ru

\section{Doi:10.5901/mjss.2014.v5n24p438}

\section{Abstarct}

The credit organizations, as one of the subjects of financial monitoring, serve as the main supplier of information to the Russian Financial Intelligence Unit database, and play a special role within national AML/CFT system. Balancing between the responsibility for compliance with anti-money laundering legislation and need to maintain the customer base, banks face additional risks that arise due to the tightening of regulatory requirements and the fierce competition in the banking market. This article discusses the structure of the national AML / CFT system, analyzes the place and role of credit institutions in the national AML / CFT. Suggests ways to optimize the performance of the credit institutions in the field of AML / CFT by establishing a mechanism of interaction of all subjects of financial monitoring.

Keywords: AML / CFT, credit organizations in the national AML / CFT system, financial monitoring, internal control system, criteria for suspicious transactions

Credit institutions are the subject of initial financial monitoring and play a special role in the national AML / CFT system. Russian banks are the main providers of information to the database of Rosfinmonitoring, what is more volume of that information increases every year: 95\% of the messages received in 2013 fell to credit institutions (Figure 1). Those figures increased by $3.2 \%$ compared with the previous year. ${ }^{1}$

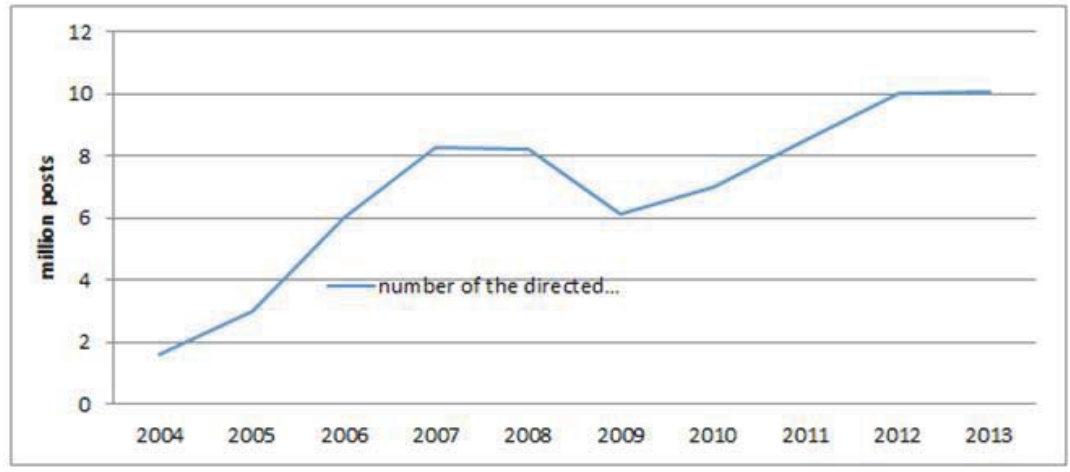

Figure 1. Dynamics of volumes of informing of Rosfinmonitoring by credit organizations ${ }^{2}$

Analysis of the activities of credit institutions in the national AML / CFT system indicates a high risk of involvement of the Russian banking sector in the scheme, aimed at the legalization of proceeds from criminal activity and the existing system to prevent this kind of attack on Russian banks needs improvement. Today the share of the Russian banking sector involvement in crimes related to money laundering is quite high. According to the Russian Interior Ministry, the situation in the credit and financial sphere is the most crime from the perspective of money laundering: it accounts for

1 Official website of the Federal Service for Financial Monitoring. Access mode: http://www.fedsfm.ru

${ }^{2}$ Compiled by the authors according to annual reports of Rosfinmonitoring 
$35.8 \%$ of the total identified in various sectors of the economy of crime. ${ }^{3}$ The Federal Service for Financial Monitoring conducts financial investigations in coordination with federal executive authorities based on data received from credit institutions. Total amount of financial investigations through combating money laundering has increased in 2013 by $11 \%$ in relation to 2012 which was more than 30 thousand Investigations. (Figure 2). ${ }^{4}$

Analysis of data shows that the percentage of the number of transferred material on completion of the investigation to the total number of financial investigations is extremely small, that suggests a large amount of information from the banks and nonoptimal efficiency of the Federal Financial Monitoring Service. In our opinion one of the reasons for this situation is that the state has taken over the functions of criminal law and administrative suppression of criminal abuse in the banking sector, while most of the work on the organization of the system detect and legislator laid prevent this kind of criminal assault mainly on the banks.

Feature of the national AML / CFT system is the absence of the principle of feedback between the public and the banking sector, i.e. the principle of one-way interaction, namely the detection of bank operations subject by the money laundering legislation bank forms and sends information about the operation to the Federal Financial Monitoring Service. However, there is no notices or directives from the Federal Financial Monitoring Service of the measures to be taken in relation to the customer. The current practice, in our opinion, leads to an increase in disparities between the number of incoming messages from banks and the number of actions taken against violators legislation by the Federal Financial Monitoring Service.

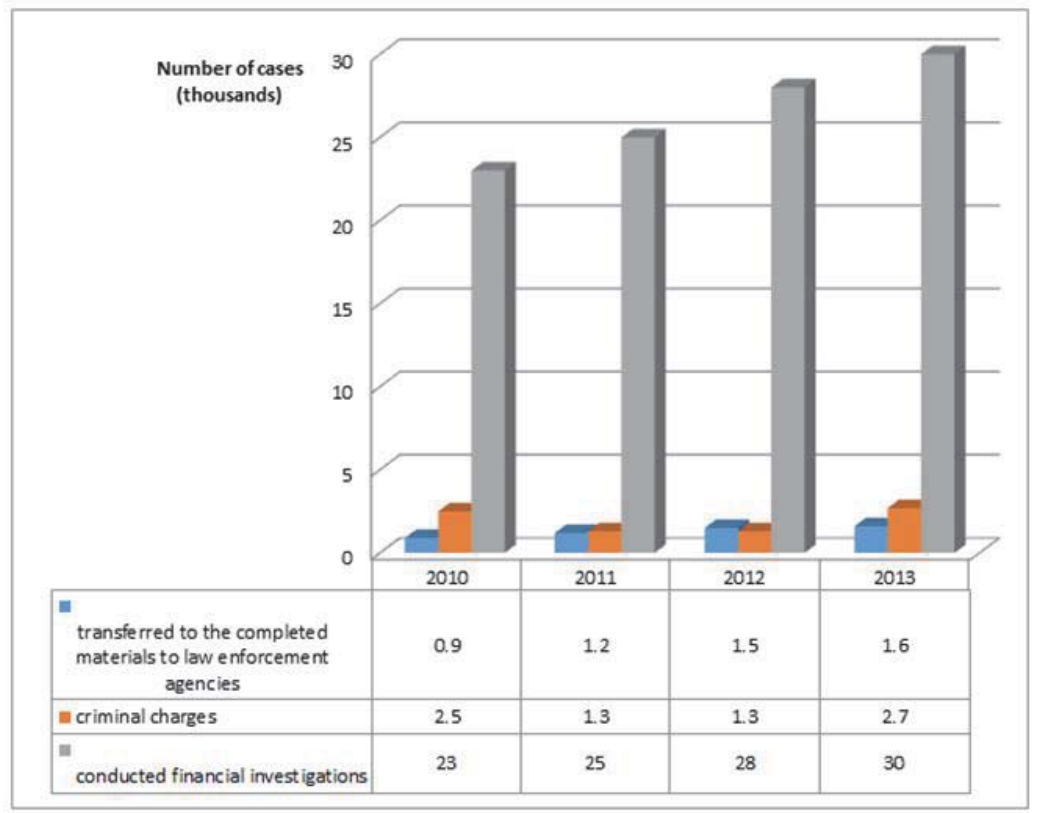

Figure 2. Results of operations Rosfinmonitoring based on information received from credit institutions. ${ }^{5}$

In our opinion, the organization of interaction of the controller and agents of financial monitoring should be amended as follows: first - a legal requirement "feedback" between the links of the AML / CFT; the second - to the approach of informing about the "suspicious transaction" approach to information about "suspicious customers." In this case, it is crucial to identify specific legislative action (penalties), undertaken by credit institutions in respect of "unscrupulous" customers. As such sanctions can serve as the introduction of a client into a single database of undesirable clients, which will be available for use by all entities of financial monitoring. We represent the possible structure of the organization's internal control system for AML / CFT in a commercial bank, provides for a "feedback" (in the form of evaluation of the AML / CFT, the direction of the recommendations create a database of undesirable clients, etc.) from the regulator (Figure 3).

3 Official website of the Ministry of Internal Affairs of the Russian Federation. Access mode: http://mvd.ru

4 Official website of the Federal Service for Financial Monitoring. Access mode: http://www.fedsfm.ru

${ }^{5}$ Compiled by the authors according to annual reports of Rosfinmonitoring 


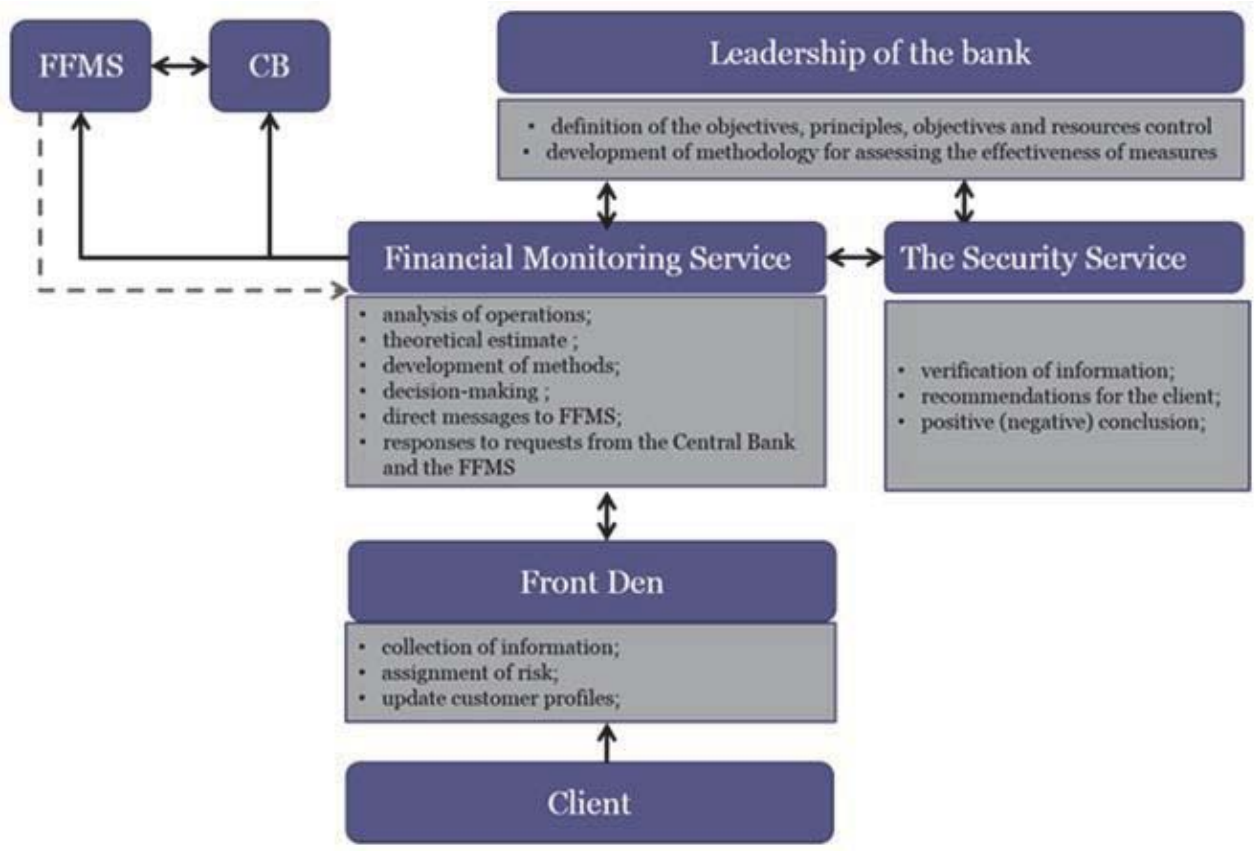

Figure 3. Structure of the organization's internal control system for AML / CFT in a commercial bank. Compiled by the authors.

In our opinion, one of the main conditions for effective functioning of the system is independent of the direction from the other activities of the bank. Responsibility for internal control in the AML / CFT system and risk management of the bank involvement in these processes is on the head / board of directors of the credit institution. Division of internal control, a strategy for risk management of the bank involvement in the process of money laundering, which includes a set of rules on the basis of which decisions are made and how to select the option of these solutions (strategy, risk tolerance, or, on the contrary, the strategy of containment of risk). In this case, the approach developed by the bank must give the bank's management to conduct a differentiated policy against customers so that the risks assumed by banks correlated with the income from the provision of banking services. All data obtained during the identification and study of the client, shall be entered in the electronic application form, to which employees will have permanent access to the online mode, in order to inform the risk management process involving the bank in the process of money laundering. Financial Monitoring Service of the bank, conducting testing procedures for a specific client to sign compliance of its operations criteria of suspicious transactions (transactions) as defined by law, request the documents proving the legitimacy of the activities of the client and analyzes the operations of all of its accounts. In this case, coordination is required with the security of the bank to verify the authenticity of documents, check for negative information to the client and to make a positive (negative) decision on its operations.

Law established a mandatory grounds for banks documenting information on a number of transactions, the terms of which the commission to refer them to the transactions carried out for ML / FT. Obviously, some of these in the Act do not have reason to objective criteria, and the development of such criteria directly assigned at the discretion of the banks. In this case, the imperfection of the legislation, in our view, is that there are no uniform criteria clearly defined, and the unity of approaches to determining the nature of the transactions carried out since in some workers with respect to the transaction may have suspicions, and others, the same transaction will not cause them. Therefore, informing the authorized authority will largely depend on the evaluation and appreciation of specific employees of the bank, i.e. would be devoid of objectivity, uniformity of approach and provide the opportunity to create an environment involving employees of the bank, and, consequently, the bank, in the criminal scheme. In order to prevent the dual interpretation of the legislation, propose the creation of a closed list of criteria for suspicious transactions, regularly edited, depending on the economic situation in the country and the world.

So, on the one hand, credit institutions as agents of the national AML / CFT have to comply with the requirements of the money laundering legislation because their activities are associated with a high risk of involvement in the process of legalization of proceeds from crime. On the other hand, in a competitive environment for Russian banks need to 
maintain and expand its customer base in order to improve business - performance and maintain a stable position in the banking market. In the course of finding the optimal balance between these objectives, the commercial banks face additional risks being subjected to sanctions by the regulator as a result of improper performance of duties in the field of AML / CFT, unconscious involvement of the bank in the process of money laundering and the risk of churn as a result of loss of goodwill. In view of the foregoing, in our opinion, the Russian banking system need the introduction of a list of "negative customers" as defined by legislation, which will allow banks to carry out activities in the field of AML / CFT in conditions of equal competition. In this case, clients who are illegal activities, will eventually be removed from the credit and finance, as subjects of financial monitoring, guided by this list will be able to refuse service in a timely manner potentially unwanted customers. On the other hand, the presence of a closed list of criteria for suspicious transactions and the use of common approaches to determining the nature of the transactions carried out, to avoid subjectivity in shaping decisions on the identified operations and minimize the risk of commercial bank involvement in the illegal scheme.

\section{References}

Lebedeva M.E., Vagizova V.I. Regional banks as one of the most important components of the banking system of Russia // Publisher of the State Institute of Economics, Finance, Law and Technology, Gatchina. Journal of Legal and Economic Studies. - 2013. - № 2;

Official website of the Bank of Russia. Access mode: http://www.cbr.ru

Official website of the Federal Service for Financial Monitoring. Access mode: http://www.fedsfm.ru

Official website of the Ministry of Internal Affairs of the Russian Federation. Access mode: http://mvd.ru

The federal Law of 02.12.1990 № 395-1 « On Banks and Banking Activity"

The federal Law of 07.08 .2001 № 115 "On counteraction to legalization of proceeds from crime and financing of terrorism" 